\title{
MAKE SURE THE JOURNAL REACHES YOU
}

This is the last issue of the ICCA Journal to appear in 1993. Your membership has formally expired by December 31, 1993. In 1993 you should have received four Journals as due to you under your membership. In order to receive all issues of the 1994 Journal, you should subscribe as an ICCA member. The (renewal) fee is now Dutch florins (Hfl.) 50.--, UK $£ 20 .--$ or US \$ 30.--. This annual fee is valid for the year 1994 and has been confirmed for the period 1993-1995 at the Triennial Meeting in Madrid, Spain in November 1992. For subscriptions, renewals and orders of back issues, readers in North America and the United Kingdom should send their orders and payment to

\author{
ICCA \\ c/o D.F. Beal \\ Dept. of Computer Science, Queen Mary and Westfield College \\ Mile End Road, London E1 4NS / England \\ Email: icca@dcs.qmw.ac.uk
}

Payment may be made as follows: UK pounds or US dollars, cash; cheques for UK pounds, from a UK bank account, or Eurocheque only; cheques for US dollars, from a North American bank.

For all other subscriptions, renewals and orders of back issues, readers should send their orders and payment to

ICCA

c/o Prof.dr. H.J. van den Herik

University of Limburg, Dept. of Computer Science

P.O. Box 616, 6200 MD Maastricht / The Netherlands

Email: icca@cs.rulimburg.nl

Payment may be made as follows: Dutch guilders, cash or Eurocheque: Hfl. 50.--; Dutch guilders, direct bank transfer from abroad: Hfl. 65.--; all other cheques: Hfl. 70.--.

Though it is primitive, valid banknotes in UK pounds, US dollars, or Dutch guilders are still the most effective way of paying your dues neatly and safely. Also it is the cheapest way to transfer your dues free of all charges to the ICCA. Of course, postal regulations require that banknotes are sent by registered mail.

For the convenience of readers in countries allowing direct transfer to Dutch banks, payment may be made to the ABN/AMRO bank, account no. 450790 878, Maastricht, Helmstraat. If desired, a transfer to postal giro account no. 1050085 of the ABN/AMRO bank is acceptable, provided the ABN/AMRO account number and the name of the ICCA are mentioned. While being acceptable, this method imposes charges on the ICCA and payment should be increased by Dfl. 15.-- to compensate.

It is vital that the cheque either be from a bank of the same country as the currency, or be a Eurocheque. International money orders are acceptable only if made out to Prof.dr. H.J. van den Herik by name. We regret that no other form of payment is acceptable.

Please include a correct statement of your mailing address. (We keep receiving payments without addresses!) Should your mailing label be erroneous or when changing residence, please return an amended label to Don Beal or Prof.dr Van den Herik as the case may require. Those using Eurocheques for their payment are requested to fill in the 4-digit validation number on the back of their cheques. Otherwise, we cannot cash them.

While stocks last, back issues of the ICCA Journal as from Vol. 6, No. 3 (August 1983) up to Vol. 16, No. 4 are still available at US \$ 6.-- each, US \$ 20.-- for any four and US \$ 180.-- for the set up to Vol. 16, No. 4. Please order these as you would order or renew a subscription.

Institutional Membership is at US \$120.-- per year and includes six copies of each issue of the Journal. Library subscriptions are US $\$ 60 .--$ per year. A replacement copy for libraries is rated at US $\$ 15 .-$ including handling and mailing. 


\section{ADDRESSES OF AUTHORS}

John Nunn

228 Dover House Road

London SW15 5AH / UK

Gennady Timoshchenko

P.O. Box 403

Novosibirsk 99 / 630099 CIS

Hiroyuki Iida

Tokyo University of

Agriculture and Technology

Faculty of Technology

2-24-16 Naka-machi, Koganei

Tokyo 184 / Japan

Jos Uiterwijk

University of Limburg

Dept. of Computer Science

P.O. Box 616

6200 MD Maastricht / The Netherlands

Prof.dr. I.S. Herschberg

Delft University of Technology

Dept. of Computer Science

Julianalaan 132

2628 BL Delft / The Netherlands

Peter van Diepen

Houtmanstraat 9

1817 EK Alkmaar / The Netherlands

Göran Grottling

Diabasvägen 3

S-43732 Lindome / Sweden
Jan Louwman

Bing Crosbystraat 5

3069 XN Rotterdam / The Netherlands

Christopher Chabris

P.O. Box 2967

Harvard Square Station

Cambridge, MA 02238 / USA

Danny Kopec

Dept. of Computer Science

United States Coast Guard Academy

15 Mohegan Avenue

New London, CT 06320-4195 / USA

Josep Parés and Teresa Canela

c/o Chessformat

Aragón 390

S. Atico 14

08013 Barcelona / Spain

Frederic Friedel

Hollenstedterstrasse 57

D-21255 Dohren / Germany

Dieter Steinwender

Computer Schach und Spiele

Entenweg 34

D-2000 Hamburg 53 / Germany

Thoralf Karlsson

Uttermarksgatan 31C

S-63351 Eskilstuna / Sweden

The addresses of authors not mentioned above will be found elsewhere in this issue of the Journal.

The deadline for copy for the next issue is February 15, 1994.

Please submit contributions and correspondence to:

Prof.dr. H.J. van den Herik
University of Limburg
$\begin{array}{ll}\text { Faculty of General Sciences } \\ \text { Department of Computer Science } \\ \text { Correspondence address: } & \text { P.O. Box } 616 \\ & 6200 \text { MD Maastricht } \\ \text { Residential Address: } & \text { Kapoenstraat } 2 \\ & 6211 \text { KW Maastricht } \\ \text { Telephone: } & +3143883477 \\ \text { Email: } & \text { icca@cs.rulimburg. nl } \\ \text { Fax: } & +3143252392\end{array}$

Intending contributors from the US or Canada may submit their copy to Professor Marsland, University of Alberta, Department of Computer Science, Edmonton, Alberta T6G 2H1 Canada.

Please address all material to be reviewed, digested or abstracted, when in English, to Professor Marsland, when in other languages to Dap Hartmann, Sterrenwacht Leiden, University of Leiden, P.O. Box 9513, 2300 RA Leiden, The Netherlands. 